\title{
Surgical Management of Intestinal Foreign Body Obstruction in Labrador Retriever Dog- A Case Report
}

\author{
B. M. Nijin Jos* \\ Veterinary Surgeon, District Veterinary Centre, Kollam \\ Kerala Animal Husbandry Department, India \\ *Corresponding author
}

\section{A B S T R A C T}

\section{Keywords}

Pet animals, Foreign body obstruction, Radiographic examination, Laparotomy

\section{Article Info}

Accepted:

22 June 2020

Available Online:

10 July 2020
Foreign body obstruction is mainly presented as an emergency condition in dogs and cats. The condition is mostly commonly seen in young playful pet animals. An eight months old Labrador retriever dog presented with the complaint of persistent vomiting and absence of defaecation was subjected to physical and radiographic examination to tentatively diagnose the condition as foreign body obstruction. The animal was subjected to exploratory laparotomy to remove the foreign body and thereby confirming the tentative diagnosis. Post operatively the patient was maintained in fluids, antibiotics and other supportive therapy for five days. The animal was reported to have recovered uneventfully.

\section{Introduction}

Foreign body obstruction is mainly found as medical emergency in dogs and cats. The playful nature of them often leads to this condition (Tripati et al., 2010 and Uma Rani et al., 2010). The foreign bodies become a medical emergency when the ingested foreign body becomes strangulated in some point of the alimentary tract. Most commonly such type of obstruction is seen in the small intestinal region where the lumen diameter becomes narrower. An 8 month old Labrador retriever presented with the complaint of persistent vomiting and absence of defaecation was subjected to physical and radiographic examination and was diagnosed as foreign body obstruction. An emergency laparotomy was done to recover the foreign body.

\section{Materials and Methods}

\section{Anamnesis and diagnosis}

An eight months old Labrador retriever dog was presented with the complaint that the animal is exhibiting persistent vomiting and 
absence of defaecation. Physical and radiographic examination diagnosed the condition as foreign body obstruction in the small intestine.

\section{Surgical procedure}

The animal was premedicated with atropine hydrochloride at the dose rate $0.045 \mathrm{mg}$ per kilogram body weight and xylazine hydrochloride at the rate of $1.5 \mathrm{mg}$ per kilogram body weight intramuscularly. The anaesthesia was induced with ketamine hydrochloride at a dose rate of $5 \mathrm{mg}$ per kilogram body weight intramuscularly and diazepam at the dose rate $0.2 \mathrm{mg}$ per kilogram body weight intravenously. The anaesthesia was maintained with ketamine: diazepam $1: 1(\mathrm{v} / \mathrm{v})$ as intravenous injection 'to effect'.

The surgical site was clipped shaved and prepared aseptically, for mid ventral laparotomy. A skin incision was made between the xiphoid and umbilicus. The linea alba was exposed and a knick incison was made in the linea alba and it was extended with scissors. The intestinal loops were exteriorized to locate the foreign body. The foreign body was found lodged in the jejunum. After locating it, the loops were placed back into the abdominal cavity. Doyens Clamp was applied on either side of the foreign body and thoroughly packed to prevent the spillage into the abdominal cavity. An incision was made in the anti mesenteric border of intestine. A stone measuring around $5 \mathrm{~cm}$ in diameter was recovered from the intestinal lumen. The incision was closed in a double inversion suture pattern. Replaced the intestinal loop back into the abdominal cavity and muscle and skin were apposed in a routine manner. Post operatively the animal was maintained on fluids, antibiotics and supportive therapy for five days. Oral feeding was started on the third day.

\section{Results and Discussion}

An eight months old Labrador Retriever dog presented with persistent vomiting and absence of defaection was diagnosed as foreign body obstruction following physical and radiographic examination. The animal was subjected to laparotomy to remove the stone that was strangulated in the intestine. Post operatively the animal was maintained on fluids, antibiotics and other supportive therapy for five days. The animal was reported to have recovered uneventfully.

Fig.1 Radiograph showing the presence of foreign body

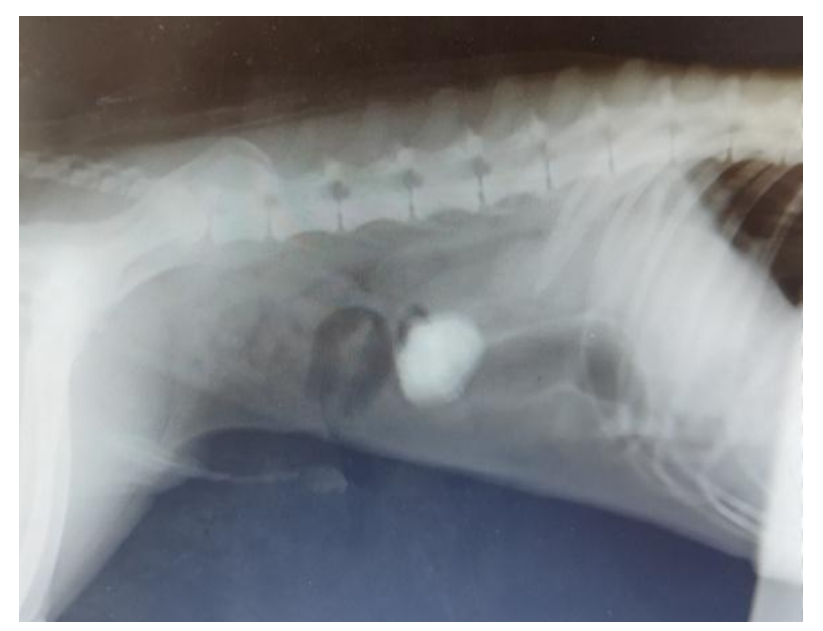




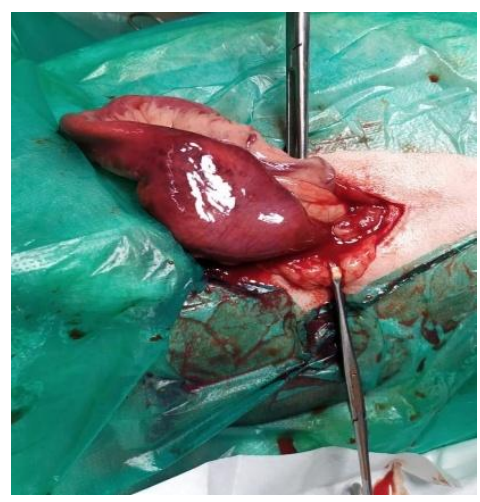

Fig.2 Exteriosed intestinal loop with the foreign body

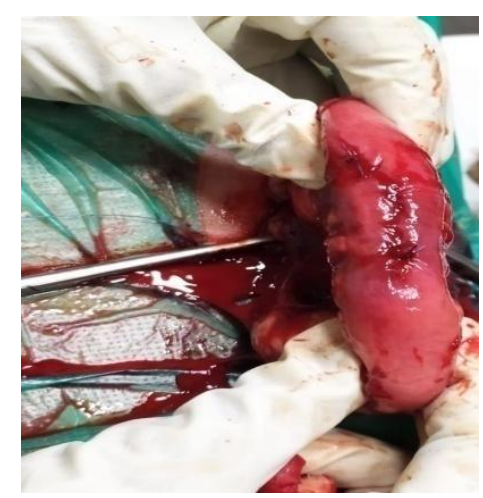

Fig.3 Intestinal incision after removing the foreign body and suturing

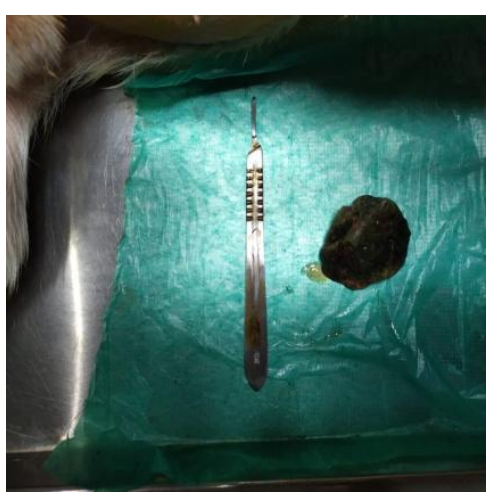

Fig.4 Foreign body after the removal
Foreign body obstruction can be considered as a medical emergency. The playful habit in the animals is the most common reason for this condition (Tripati et al., 2010 and Uma Rani et al., 2010) especially when ingested object's diameter exceeds the lumen diameter of the alimentary tract. According to Boag et al., (2005) the gastrointestinal obstruction often leads to electrolyte and acid base imbalance which lead to the development of an emergency situation and pose a threat to the animals life. Perforations and subsequent peritonitis can become fatal to the life of the patient (Evans et al., 1994). Prompt presentation, diagnosis and surgical intervention play a major role in the positive outcome in case of gastro intestinal obstructions (Hayes, 2009).

\section{Acknowledgement}

The author would like to thank Director, Kerala Animal Husbandry Department, District Animal Husbandry Officer, Kollam and Chief Veterinary Officer, District Veterinary Centre Kollam for providing the facilities for the successful completion of the work.

\section{References}

Boag, A.K. Coe, R.J. Martinez, T.A. and Hughes, D. 2005. Acid-base and electrolyte abnormalities in dogs with gastrointestinal foreign bodies. J. Vet. Inter. Med. 19. 816-821.

Evans, K.L.,Smeak, D.D. \& Biller, D.S. 1994. Gastrointestinal linear foreign bodies in 32 dogs: a retrospective evaluation and feline comparison. J. American Anim. Hospital Asso. 30. 445-450.

Hayes G. 2009. Gastrointestinal Foreign Bodies in Dogs and Cats: A Retrospective Study of 208 Cases. J. Small Anim. Pract. 50(11): 576-583.

Tripathi, A.K., Soodan, J.S. and Kushwaha, R.B. 2010. Gastric foreign body syndrome in a Golden Retriever dog. Intas Polivet. 11 (II): 305-306.

Uma Rani, R., Vairavasamy, K. and Muruganandan, B. 2010. Surgical management of gastric foreign bodies in pups. Intas Polivet. 11 (II): 302-303.

\section{How to cite this article:}

Nijin Jos, B. M. 2020. Surgical Management of Intestinal Foreign Body Obstruction in Labrador Retriever Dog- A Case Report. Int.J.Curr.Microbiol.App.Sci. 9(07): 3646-3648. doi: https://doi.org/10.20546/ijcmas.2020.907.426 